\title{
Pt Electrocatalysts Composited on Electro-Spun Pt Nanowires for Direct Methanol Fuel Cells
}

\author{
Geon-Hyoung An and Hyo-Jin Ahn ${ }^{\dagger}$ \\ Department of Materials Science and Engineering, Seoul National University of Science \\ and Technology, Seoul 139-743, Korea
}

(Received July 10, 2012 : Received in revised form July 19, 2012 : Accepted July 28, 2012)

\begin{abstract}
Two types of Pt nanoparticle electrocatalysts were composited on Pt nanowires by a combination of an electrospinning method and an impregnation method with $\mathrm{NaBH}_{4}$ as a reducing agent. The structural properties and electrocatalytic activities for methanol electro-oxidation in direct methanol fuel cells were investigated by means of scanning electron microscopy (SEM), high-resolution transmission electron microscopy (HRTEM), X-ray diffraction (XRD), X-ray photoelectron spectroscopy (XPS), and cyclic voltammetry. In particular, SEM, HRTEM, XRD, and XPS results indicate that the metallic Pt nanoparticles with polycrystalline property are uniformly decorated on the electro-spun Pt nanowires. In order to investigate the catalytic activity of the Pt nanoparticles decorated on the electro-spun Pt nanowires, two types of $20 \mathrm{wt} \% \mathrm{Pt}$ nanoparticles and $40 \mathrm{wt} \% \mathrm{Pt}$ nanoparticles decorated on the electro-spun Pt nanowires were fabricated. In addition, for comparison, single Pt nanowires were fabricated via an electrospinning method without an impregnation method. As a result, the cyclic voltammetry and chronoamperometry results demonstrate that the electrode containing $40 \mathrm{wt} \% \mathrm{Pt}$ nanoparticles exhibits the best catalytic activity for methanol electro-oxidation and the highest electrochemical stability among the single $\mathrm{Pt}$ nanowires, the $20 \mathrm{wt} \% \mathrm{Pt}$ nanoparticles decorated with Pt nanowires, and the $40 \mathrm{wt} \% \mathrm{Pt}$ nanoparticles decorated with $\mathrm{Pt}$ nanowires studied for use in direct methanol fuel cells.
\end{abstract}

Key words fuel cell, electrospinning, nanowires, Pt catalysts, methanol electro-oxidation.

\section{Introduction}

Among the various existing fuel cells, direct methanol fuel cells(DMFCs) have recently attracted considerable interest owing to several advantages such as high energy density, low operating temperatures, and easy storage of fuels. ${ }^{1,2)}$ However, before DMFCs can be employed in industrial applications, some issues such as the low electrocatalytic activity at the anode, fuel cross-over, high price of electrocatalysts, and limited supply of electrocatalysts must be resolved. In particular, one of the key factors for the improvement of DMFC performance is to enhance the catalytic activity of the electrocatalysts used as the anode. To date, significant effort has been directed at improving the catalytic activity of methanol electrooxidation. One possible approach towards this end involves modification of existing electrocatalysts by the use of supporting materials, namely, C-based supports(CNT, Vulcan, and Graphene) and metal oxide-based supports $\left(\mathrm{RuO}_{2}\right.$ and $\mathrm{CeO}_{2}$ ), and by the use of Pt-based alloys such as PtRu and $\mathrm{PtRh}^{3-5)}$ More recently, one-dimensional nanostructures have attracted growing interest in the field of fuel cells. For example, Kim et al. synthesized Pt nanowires for use

${ }^{\dagger}$ Corresponding author

E-Mail : hjahn@seoultech.ac.kr (H. -J. Ahn) as electrocatalysts in DMFCs by electrospinning, evaluated the effects of heat treatment, and demonstrated the methanol electro-oxidation properties. $\left.{ }^{6}\right)$ Kim et al. also reported the enhancement of electrocatalytic activity for bimetallic PtRh and PtRu nanowires synthesized by electrospinning. ${ }^{7)}$ Pt nanowires electrodeposited on poly(vinylpyrrolidone) (PVP) exhibited excellent catalytic activity for methanol electro-oxidation in DMFCs as reported by Song et al. ${ }^{8)}$ However, a number of unresolved issues related to the use of one-dimensional nanostructures in DMFCs still remain. In this study, we have fabricated two types of $\mathrm{Pt}$ nanoparticle electrocatalysts decorated on electro-spun Pt nanowires and demonstrated their electrochemical properties such as methanol electro-oxidation. For comparative purposes, the single Pt nanowire electrocatalysts were fabricated by an electrospinning method. Furthermore, in order to compare the two types of Pt nanoparticle electrocatalysts decorated on electro-spun Pt nanowires, relative weights of the Pt nanoparticles to the Pt nanowires of 20 $\mathrm{wt} \%$ and $40 \mathrm{wt} \%$ were selected.

\section{Experimental Procedure}

Pt nanoparticle electrocatalysts decorated on Pt nanowires fabricated by electrospinning were prepared using an impregnation method. First, in order to fabricate 
the electro-spun Pt nanowires, a precursor solution of $\mathrm{H}_{2} \mathrm{PtCl}_{6} \cdot \mathrm{xH}_{2} \mathrm{O}$ (Aldrich) was dispersed in de-ionized water by mixing for $2 \mathrm{hrs}$. Poly(vinylpyrrolidone) (PVP, Aldrich, $\mathrm{M}_{\mathrm{w}}=1,300,000 \mathrm{~g} / \mathrm{mol}$ ) was dissolved in ethanol(Aldrich) over a period of $5 \mathrm{hrs}$. The mixture solution consisting of the two precursor solutions was loaded into a syringe and a metal orifice of the syringe was connected to a DC power supply. The feeding rate of the electro-spun $\mathrm{Pt}$ nanowires was maintained at $0.02 \mathrm{ml} / \mathrm{h}$ using syringe pump at $6.5 \mathrm{kV}$ with a syringe equipped with a 25 gauge. The distance between the needle tip and the collector was fixed to $\sim 8 \mathrm{~cm}$. In order to remove the PVP polymer, the as-spun samples were calcined at $400^{\circ} \mathrm{C}$ for $2 \mathrm{~h}$ in air. The electro-spun Pt nanowires were then dispersed in $0.1 \mathrm{mM}$ $\mathrm{H}_{2} \mathrm{PtCl}_{6} \cdot \mathrm{xH}_{2} \mathrm{O}$ and $0.2 \mathrm{mM} \mathrm{H}_{2} \mathrm{PtCl}_{6} \cdot \mathrm{xH}_{2} \mathrm{O}$ solutions, respectively, for $1 \mathrm{~h}$ at room temperature, in order to fabricate $20 \mathrm{wt} \%$ Pt nanoparticles(referred to as sample A) and $40 \mathrm{wt} \% \mathrm{Pt}$ nanoparticles(referred to as sample B) on the electro-spun $\mathrm{Pt}$ nanowires. Subsequent addition of concentrated $\mathrm{NaBH}_{4}$ solution as a reducing agent $(100$ $\mathrm{mg} / \mathrm{ml}$ ) resulted in the formation of Pt nanoparticles on the electro-spun Pt nanowires. After a $6 \mathrm{~h}$ incubation period, the resultant samples were washed several times with de-ionized water and freeze-dried at $-60^{\circ} \mathrm{C}$.

The morphology of the samples was characterized by scanning electron microscopy(SEM, Hitachi S-4100) and high-resolution transmission electron microscopy(HRTEM, JEOL-2100F, KBSI Suncheon center). The crystallinities of the samples were examined using X-ray diffraction (XRD, Rigaku X-ray diffractometer equipped with a $\mathrm{Cu}$ $\mathrm{K} \alpha$ source). The chemical bonding states of the samples were analysed by X-ray photoelectron spectroscopy(XPS, using a VG Scientific(ESCALAB 250) spectrometer with an $\mathrm{Al} \mathrm{K \alpha}$ source). Electrochemical measurements of the samples were performed with conventional three electrodes system, which consist of the as-prepared samples (working electrode), $\mathrm{Ag} / \mathrm{AgCl}($ reference electrode), and $\mathrm{Pt}$ gauze(counter electrode). The test cells were continuously purged with nitrogen gas for $1 \mathrm{~h}$ with stirring. Electrocatalyst inks consisting of catalysts and Nafion( $8: 2$ weight ratio) were loaded onto the glassy carbon working electrode $\left(0.07 \mathrm{~cm}^{2}\right)$. The electrolytes used comprised an aqueous solution of $0.5 \mathrm{M} \mathrm{H}_{2} \mathrm{SO}_{4}$ with $2 \mathrm{M} \mathrm{CH}_{3} \mathrm{OH}$. The catalytic activities for methanol electro-oxidation of the samples were characterized by cyclic voltammetry(AUTOLAB by Eco Chemie) at a scan rate of $50 \mathrm{mV} / \mathrm{s}$ in the range of -0.2 to $1.0 \mathrm{~V}$. Chronoamperometry tests were carried out at -0.5 $\mathrm{V}$ versus $\mathrm{Ag} / \mathrm{AgCl}$ in an aqueous solution of $0.5 \mathrm{M} \mathrm{H}_{2} \mathrm{SO}_{4}$ with $2 \mathrm{M} \mathrm{CH}_{3} \mathrm{OH}$, at room temperature.

\section{Results and Discussion}

Fig. 1 shows the SEM images obtained from (a) the

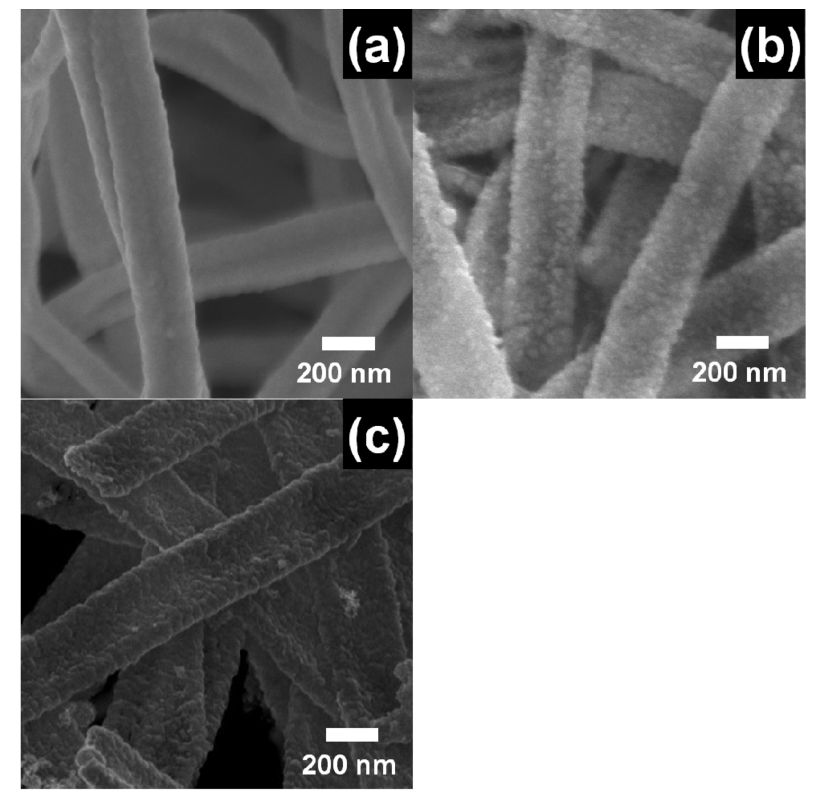

Fig. 1. SEM images obtained from (a) the single Pt nanowires, (b) sample A and (c) sample B.

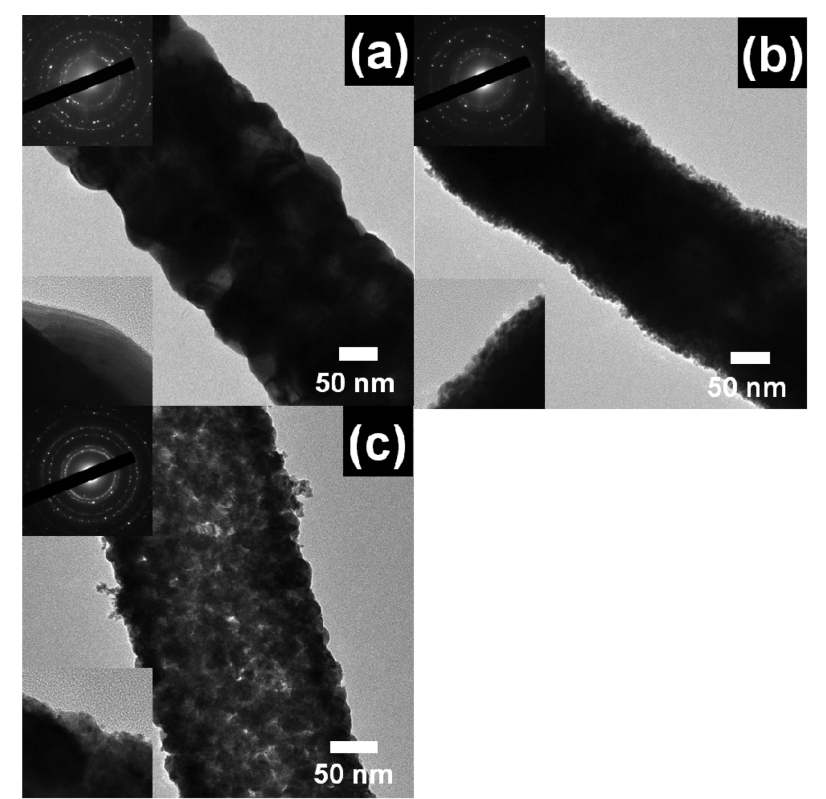

Fig. 2. HRTEM images of (a) the single Pt nanowires, (b) sample A and (c) sample B.

single Pt nanowire electrocatalysts, (b) $20 \mathrm{wt} \%$ Pt nanoparticle electrocatalysts composited on the electro-spun Pt nanowires(sample A), and (c) $40 \mathrm{wt} \% \mathrm{Pt}$ nanoparticle electrocatalysts composited on the electro-spun Pt nanowires(sample B). Fig. 1(a) shows uniform Pt nanowires having a diameter of $\sim 210-240 \mathrm{~nm}$, fabricated by electrospinning(for comparative purposes). The Pt nanowires, as shown in Fig. 1(a), have a smooth surface. Figs. 1(b) and 1(c) show hetero-structured Pt nanowire electrocatalysts having diameters of $\sim 226-279 \mathrm{~nm}$, which implies the pre- 
sence of small Pt nanoparticles decorated on the electrospun Pt nanowires. In particular, the small nanoparticles in Figs. 1(b) and 1(c) exhibit relatively bright regions, which could serve to promote superior electrocatalytic activity for the DMFCs. Overall, we fabricated two types of hetero-structured Pt electrocatalysts; the first comprises $20 \mathrm{wt} \% \mathrm{Pt}$ nanoparticles composited on the Pt nanowires (sample A) and the other is composed of $40 \mathrm{wt} \% \mathrm{Pt}$ nanoparticles composited on the Pt nanowires(sample B).

Fig. 2 shows the HRTEM images and TED(transmission electron diffraction) patterns of the samples. The single Pt nanowires fabricated by electrospinning exhibit smooth morphology in the edge regions as shown in Fig. 2(a). In the case of sample A and sample B, Pt nanoparticles on the electro-spun $\mathrm{Pt}$ nanowires are in the range of $\sim 3-4 \mathrm{~nm}$ in size as shown in the insets of Figs. 2(b) and 2(c). These results indicate that sample A and sample B exhibit rough morphology on the electro-spun $\mathrm{Pt}$ nanowires due to loading of Pt nanoparticles. In other words, the hetero-structured Pt nanowire electrocatalysts, namely, Pt nanoparticles decorated on the electro-spun Pt nanowires, exhibit better electrocatalytic activities due to the improved specific surface area when compared to the single Pt nanowire electrocatalysts. Furthermore, the TED patterns of the samples contain the diffuse ring pattern with spots around the (000) spot, indicating the polycrystalline nature of the samples.

Fig. 3 shows the XRD plots obtained for single Pt nanowires, sample A, and sample B. All of the samples exhibit diffraction peaks corresponding to crystalline $\mathrm{Pt}$ at $2 \theta=39.7^{\circ}, 46.2^{\circ}$, and $67.4^{\circ}$ (JCPDS 04-0802, space group Fm3m[225]). This implies that the crystalline Pt phases of the samples show an FCC structure. Furthermore, the peak intensity of the (111) plane at $39.7^{\circ}$ is higher than the intensity of the (200) plane at $46.2^{\circ}$ and the (220) plane

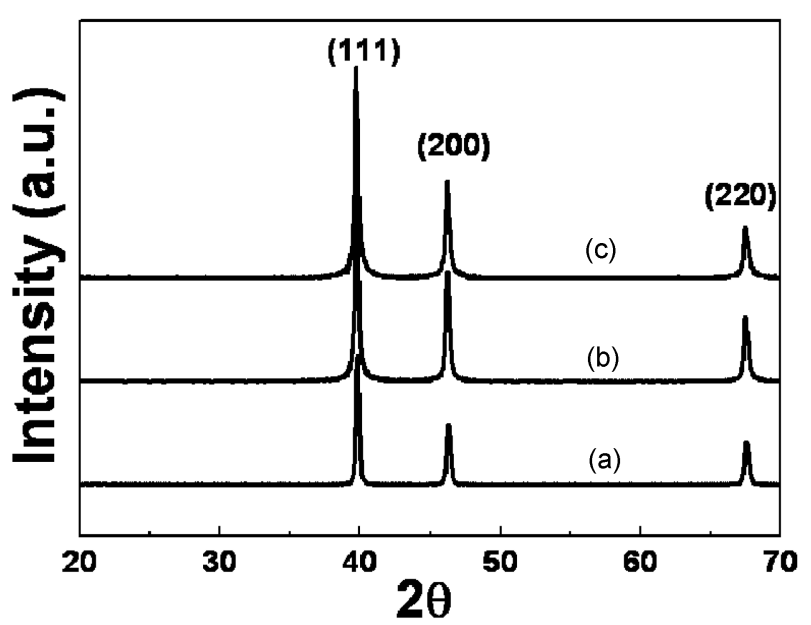

Fig. 3. Powder XRD plots of (a) the single Pt nanowires, (b) sample $\mathrm{A}$ and (c) sample B.

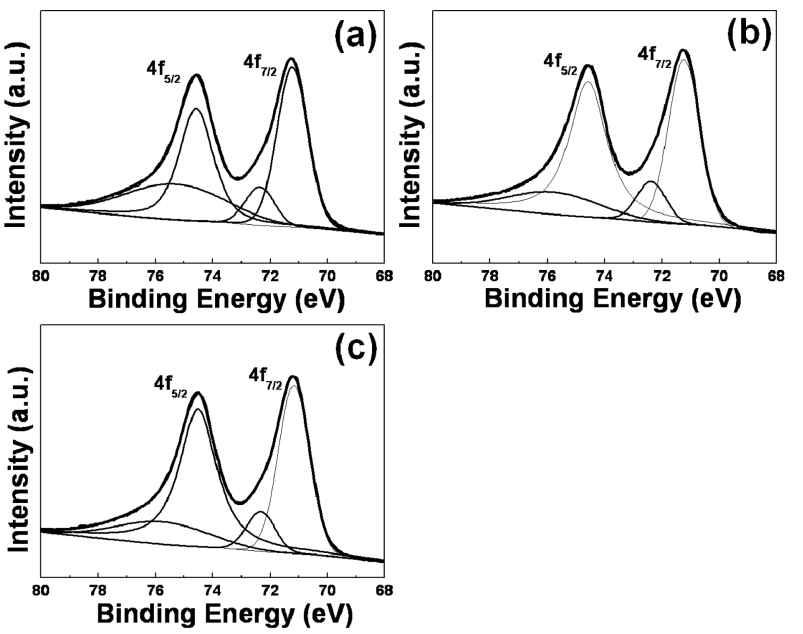

Fig. 4. XPS spectra of (a) the single Pt nanowires, (b) sample A and (c) sample B.

at $67.2^{\circ}$. This implies that the samples grow mainly along the (111) plane rather than the (200) plane and the (220) plane, which would produce superior electrocatalytic activity due to improvement of the effective catalyst atoms.

To elucidate the chemical bonding states of the samples, we performed XPS examinations. Calibration on all spectral peaks was carried out using the $\mathrm{C} 1 s \operatorname{line}(284.5 \mathrm{eV})$ as a reference for the charge collection. Fig. 4 shows that the Pt $4 f$ core levels, which are composed of two pairs of doublets, exhibit Pt $4 f_{7 / 2}$ and Pt $4 f_{5 / 2}$ photoelectrons with peaks at $\sim 71.2 \mathrm{eV}$ and $\sim 74.5 \mathrm{eV}$. This implies that the Pt phase exists as metallic Pt (0) states. ${ }^{9)}$ In addition, the second set of doublets observed at $\sim 72.4 \mathrm{eV}$ is related to $\mathrm{Pt}(\mathrm{II})$ states such as $\mathrm{PtO}$ and $\mathrm{Pt}(\mathrm{OH})_{2}{ }^{10)}$ Furthermore, it seems that Pt-oxide states are formed from oxygen sources in the precursor solutions and by exposure of the samples to air for XPS examinations. As a result, although two different kinds of Pt-metallic atoms and oxygen atoms exist on the surface of the samples, the major contribution to methanol electro-oxidation in DMFCs comes from metallic atoms on the electrocatalysts. In other words, the zero-valent metallic states on the Pt phases primarily affect the efficiency of the electrocatalysts in DMFCs.

Fig. 5 shows the cyclic voltammograms(CVs) for methanol electro-oxidation/reduction with the single Pt nanowires, sample A, and sample B, respectively, which were characterized in the range of -0.2 to $1.0 \mathrm{~V}$ at a scan rate of $50 \mathrm{mV} / \mathrm{s}$. The voltammograms of all samples were measured in a mixture solution of $0.5 \mathrm{M} \mathrm{H}_{2} \mathrm{SO}_{4}$ and $2 \mathrm{M}$ $\mathrm{CH}_{3} \mathrm{OH}$, in order to examine the catalytic activities for methanol electro-oxidation in DMFCs. For comparison, the single Pt nanowires were also used as anodic electrocatalysts for DMFCs. As previously reported, methanol reacts with water to produce $\mathrm{CO}_{2}, 6$ electrons, and 6 protons at the anode of DMFCs as follows: ${ }^{2,11-13}$ ) 

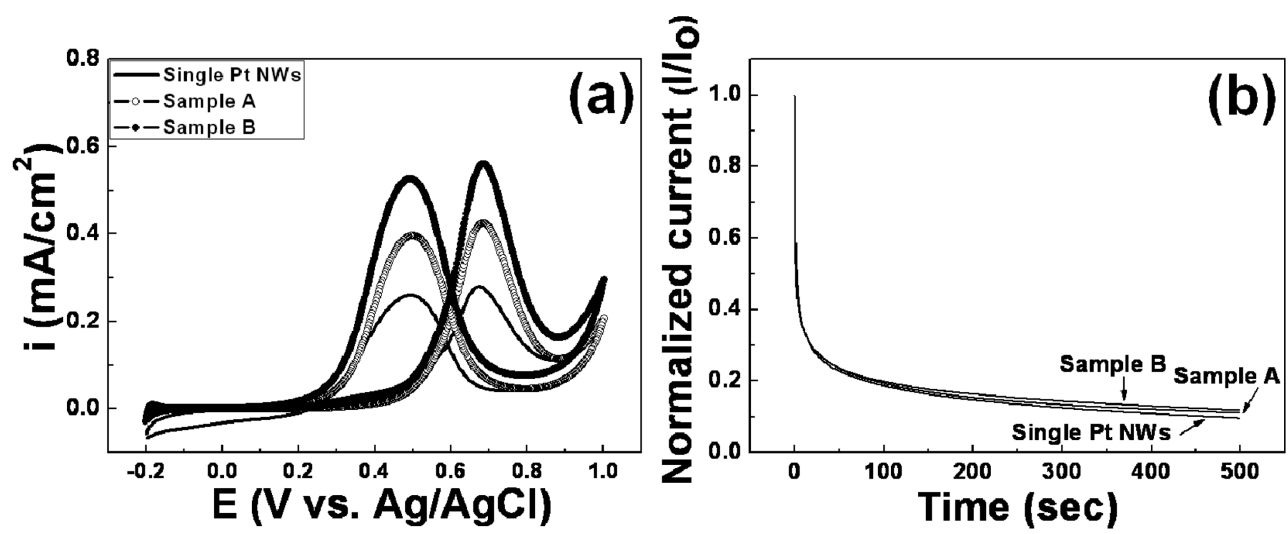

Fig. 5. (a) Methanol electro-oxidation and (b) Chronoamperometry of the single Pt NWs, sample A and sample B.

$$
\mathrm{CH}_{3} \mathrm{OH}+6 \mathrm{H}_{2} \mathrm{O} \rightarrow \mathrm{CO}_{2}+6 \mathrm{e}^{-}+6 \mathrm{H}^{+}
$$

A higher production of electrons is related to improved methanol electro-oxidation properties and high-performance of DMFCs can be attained. As shown in Fig. 5, the cyclic voltammogram for methanol electro-oxidation consists of two peaks relative to forward peaks and backward peaks. Forward peaks are related to anodic current density and backward peaks to intermediate species such as $\mathrm{CH}_{2} \mathrm{OH}, \mathrm{CHO}, \mathrm{HCOOH}$, and $\mathrm{CO}$. Therefore, the higher anodic current density corresponding to the forward peaks implies the higher methanol electro-oxidation of the electrocatalysts for DMFCs. The current densities of the single Pt nanowire electrocatalysts, sample $\mathrm{A}$, and sample B are $\sim 0.27 \mathrm{~mA} / \mathrm{cm}^{2}, \sim 0.42 \mathrm{~mA} / \mathrm{cm}^{2}$, and $\sim 0.56 \mathrm{~mA} / \mathrm{cm}^{2}$, respectively, at an accelerating voltage of $0.68 \mathrm{~V}$. Notably, sample A and B represent higher anodic current densities, which are about 1.5 times and 2.1 times comparing to those of the single Pt nanowire electrocatalysts. This implies that sample A and B have better performance as electrocatalysts than the single Pt nanowires due to the small Pt nanoparticles(ca. 3-4 nm in size) formed on the electro-spun Pt nanowires. In particular, the highest methanol electro-oxidation among the three samples was obtained with sample B. The improved methanol electrooxidation exhibited by sample B with a higher loading of Pt nanoparticles can be attributed to the combined effects of higher specific surface area and improved electrolyte/ electrode contact area. Fig. 5(b) shows the chronoamperometry profiles of the samples measured in a mixture solution of $0.5 \mathrm{M} \mathrm{H}_{2} \mathrm{SO}_{4}$ and $2 \mathrm{M} \mathrm{CH} \mathrm{CH}_{3} \mathrm{OH}$ at $0.5 \mathrm{~V}$ for $500 \mathrm{~s}$ for analysis of electrochemical stability. All samples exhibit current degradation with increasing time. However, sample B exhibits slightly slower current degradation compared to sample A and the single Pt nanowires after $500 \mathrm{~s}$. In other words, although all samples present similar oxidation current behaviour, resulting from the one-dimensional nanostructures, sample B shows the highest elec- trochemical stability among the three samples. Therefore, sample B exhibits superior methanol electro-oxidation catalytic activity and more stable electrochemical stability due to the combined effects of a higher specific surface area and improved electrolyte/electrode contact area. These results indicate that Pt nanoparticle electrocatalysts decorated on Pt nanowires may lead to the fabrication of high-efficiency direct methanol fuel cells.

\section{Conclusion}

Pt nanoparticle electrocatalysts composited on electrospun Pt nanowires were fabricated via an electrospinning method in combination with an impregnation method. The highest methanol electro-oxidation properties and best electrochemical stability were obtained at a catalyst loading of $40 \mathrm{wt} \% \mathrm{Pt}$ nanoparticles, compared to single Pt nanowires and $20 \mathrm{wt} \%$ Pt nanoparticles, which can be attributed to the presence of the Pt nanoparticles resulting in the combined effects of higher specific surface area and improved electrolyte/electrode contact area. This implies that hetero-structured Pt nanowire electrocatalysts may be an important class of electrocatalysts for use in highefficiency DMFCs.

\section{Acknowledgment}

This study was financially supported by Seoul National University of Science \& Technology.

\section{References}

1. M. Winter and R. J. Brodd, Chem. Rev., 104, 4245 (2004).

2. H. -J. Ahn, W. J. Moon, T. -Y. Seong and D. Wang, Electrochem. Comm., 11, 635 (2009).

3. E. Antolini, Mater. Chem. Phys., 78, 563 (2003).

4. H. -J. Ahn, H. -S. Shim, W. B. Kim, Y. E. Sung and T. -Y. Seong, J. Alloy. Comp., 471, L39 (2009). 
5. H, -J. Ahn, J. -S. Jang, Y. E. Sung and T. -Y. Seong, J. Alloy. Comp., 473, L28 (2009).

6. J. M. Kim, H. -I. Joh, S. M. Jo, D. J. Ahn, H. Y. Ha, S. -A. Hong and S. K. Kim, Electrochim. Acta, 55, 4827 (2010).

7. Y. S. Kim, S. H. Nam, H. -S. Shim, H. -J. Ahn, M. Anand and W. B. Kim, Electrochem. Comm., 10, 1016 (2008).

8. Y. -J. Song, S. -B. Han and K. -W. Park, Mater. Lett., 64, 1981 (2010).

9. J. F. Moulder, W. F. Stickle, P. E. Sobol and K. D. Bomben,
Handbook of X-ray Photoelectron Spectroscopy, p.180181, Physical Electronics, Eden Pairie, MN, USA (2004).

10. Z. Liu, L. Hong and S. W. Tay, Mater. Chem. Phys., 105, 222 (2007).

11. K. -W. Park, J. -H. Choi, K. -S. Ahn and Y. E. Sung, J. Phys. Chem. B, 108, 5989 (2004).

12. B. R. Rauhe, F. R. Mclarnon and E. J. Cairns, J. Electrochem. Soc., 142, 1073 (1995).

13. Y. -S. Yeom and H. -J. Ahn, Kor. J. Mater. Res., 21, 8 (2011) (in Korean). 